\title{
The Hot Water Oil Expulsion Technique for Geothermal Resources
}

\author{
Xuezhong Wang \\ Xinchun Oil Production Plant, Shengli Oilfield Company, SINOPEC, Dongying, China \\ Email:wxzxlywlt@sina.com
}

Received December 29, 2011; revised February 16, 2012; accepted March 1, 2012

\begin{abstract}
With the rapid development of Chinese petroleum industry, Oil production way of burning crude oil to produce steam need change. Heavy oil reservoir with thin layer or edgewater is unsuitable thermal recovery, electric heating leads to considerable electrical consumption, low injection water temperature decreases reservoir temperature and increased crude oil viscosity. The prolonged temperature difference break up reservoir pore throat cement and framework minerals. To improve high-capacity channel communication, we proposed geothermal oil recovery. Broad-sense abundant geothermal resources and existing injection water technique equipment are used, deep-seated high temperature liquid (oil-gas-water mixture) draws geothermal warming flowing layer to transit heat upward, decreases viscidity and increases fluidity. Reservoir temperature different offer geothermal fountain. Practicability process is analyzed. statistics and reservoir temperature variation analysis of Gudong Oilfield, Shengli Oilfield Company, SINOPEC, we have designed flow-chart concept for geothermal oil recovery, suggested drilling multi-branch well in heavy oil reservoir as injection-well, at the same position of geothermal fountain well, using free-pressure pump to inject hot liquid directly to aimed oil layer, made oil recovery in surrounding wells. It is proposed that geothermal oil recovery forerunner test should be first conducted in favorable blocks.
\end{abstract}

Keywords: Geothermal Energy; Oil Recovery; Hot Water Process; Thermal Process; Water Flood Recovery

\section{Introduction}

Chinese petroleum industry has suffered from the global economic crisis currently. One hand, we safeguard countries event of crude oil from commingled production. On the other hand, we increase reservoir recovery, costsaving and profit-increasing by concept innovation, thinking innovation, management innovation and technological innovation. The paper based on water drive and cyclical steam stimulation; analyze geothermal energy mechanism and of hot water process effect, compared with water drive and cyclical steam stimulation;analysis geothermal resources, demonstrate hot water oil expulsion feasibility technique for geothermal resources.

\section{Necessity Analysis}

Energy-saving and environmental protection became key problem of macro-control, some traditional practices need reflection and improvement. For example, heavy oil is hard to extract due to high viscosity, is hard to refine due to impurities. However, heavy oil attracts more and more attention by oil prices continued rise and huge resources amount. Produce heavy oil core is reduce oil viscosity, also significantly reduce oil viscosity, brilliant achievements on recovering heavy oil as steam stimulation, steam flooding, electrical heating in recent years. In China, more than 90\% recovered heavy oil depend on steam stimulation or steam drive, recovery is $30 \%$. W ell pattern optimization adjustment for heavy oil thermal recovery reservoir horizontal well developed technical and economic policy research, the whole process of oil layer protection technique, uniform steam injection in horizontal wells, assistant thermochemical technology in heavy oil steam soaking, viscosity reduction by electric heating technology, supportted heavy oil production realize sustained growth. With energy saving and reduction of pollution in China, petroleum production methods through burning crude oil to produce steam needs change. At the same time, thin beds and heavy oil reservoirs with edge water driving unsuitable for thermal recovery. Compare to water flooding reservoir, heavy oil block faces high heating costs, low utilization of conflict hot urgent need to reduce thermal production cost.

Water flooding is dominating oilfield development method in Chinese Oilfields, its average recovery is around $33 \%$. Flooding water temperature is significantly lower than oil temperature, caused oil layer temperature lower and increase crude oil viscosity. The severe tem- 
perature fluctuation leads to break reservoir pore cement and matrix minerals, intensify large channel channeling flows and reduce oil recovery. During water flooding process unit development in Gudong Oilfield along with formation temperature lower, Guantao formation (reservoir depth is $1350 \mathrm{~m}$ ) is taken as example, initial formation temperature is $66.0^{\circ} \mathrm{C}$, present formation temperature is $62.3^{\circ} \mathrm{C}$, decreased $3.7^{\circ} \mathrm{C}$. Formation temperature decreased $0.81^{\circ} \mathrm{C}$ compared between 2006 and 2003 (Table 1), mainly because injection water temperature is significantly lower than formation temperature. Corresponding, Gudong Oilfield crude oil viscosity increased, average $874 \mathrm{mPa} \cdot \mathrm{s}$ at early stage, in later stage is 1067 $\mathrm{mPa} \cdot \mathrm{s}$, presently $1874 \mathrm{mPa} \cdot \mathrm{s}$. Geothermal gradient is $3.519^{\circ} \mathrm{C} /(100 \mathrm{~m})$ of Dongying Formation, Shahejie Formation in Gudong Oilfield at present, formation temperature does not significantly lower than initial formation temperature, which depended on natural energy, less injected water affected. The severe temperature fluctuation leads to break reservoir pore cement and matrix minerals, intensify large pore channeling and reducing sweep efficiency and oil recovery.

Professor Yu Qitai considered, water flooding development are corresponding to cold water on displacement, cold water cool oil layer, increased oil viscosity, changed oil-water phase permeability, result oil displacement efficiency reduce $2 \%-8 \%$ [1]. Strong natural water-flood is water displacing oil process with isothermal forging temperature, water flooding is equal to displacing oil by low salinity water, resulting displacement efficiency reduce $4 \%-10 \%$. Strong natural water-flood is water displacing oil process with high salinity water. Differences make the displacement efficiency strong natural water-flood is higher than water flooding. To improve highcapacity channel communication, we proposed methods for concerning geothermal oil recovery. The broad-sense abundant geothermal resources and existing injection water technique equipment are used, deep-seated high temperature liquid (oil-gas-water mixture) draws geothermal warming flowing layer to transit heat upward, decrease viscidity and increase fluidity. Layers different in temperature offer geothermal fountain. Practicability process is analyzed.

Earth riched in geothermal resources, such as volcanic

Table 1. Reservoir temperature year-by-year changes in Gudong Oilfield.

\begin{tabular}{ccccc}
\hline contrast, each year. & 2003 & 2004 & 2005 & 2006 \\
\hline $\begin{array}{c}\text { number of samples (number) } \\
\text { geothermal gradient } \\
\left({ }^{\circ} \mathrm{C} /(100 \mathrm{~m})\right) \\
\begin{array}{c}-1350 \mathrm{~m} \text { formation } \\
\text { temperature }\left({ }^{\circ} \mathrm{C}\right)\end{array}\end{array}$ & 336 & 981 & 1022 & 561 \\
\hline
\end{tabular}

eruptions, focus on geothermal energy release. Geothermal energy used in heating, power generation, hot spring [2-4]. In Hawaii, people have used "hot dry rock" to build artificial mining geothermal heat reservoir, water is injection into superheated crystal rocks, heated by hot rocks, hot water with $71^{\circ} \mathrm{C}$ back to surface by production wells, for power generation or building heating. Yambajan geothermal riched resources in Tibet, the second geothermal reservoir depth is $1850 \mathrm{~m}$, the highest temperature up to $329^{\circ} \mathrm{C}$ [5]. Direct collection and use geothermal resources is very good, but geothermal resources cannot completely replace crude oil, uneasy to carry crude oil and derivatives, can use hot water flooding by geothermal resources? Steam stimulation process need burn a lot of crude oil, steam injection process thermal efficiency is relatively low, therefore, burning oil to generate steam to achieve heavy oil thermal recovery development methods need change. At the same time, reservoir temperature drops by cold injury for low water injection well temperature has reached a broad consensus in China. An important constraining factor in water flooding temperature is significantly lower than oil temperature, caused oil layer temperature decrease and increase crude oil viscosity. Therefore, we should improve injecting water temperature, water flooding temperature is higher than reservoir temperature are best. Base on above studying, we conclude that geothermal resources can be used to produce oil, carried out the feasibility study of hot water oil expulsion technique for geothermal resources.

\section{Feasibility Study}

\subsection{Method Principle}

Geothermal resources refers to geothermal energy, geothermal fluids and useful components come from crust adapt current technology economic conditions. Geothermal energy is a new clean energy, inexpensive and use directly. The broad-sense abundant geothermal resources and existing injection water technique equipment are used, the deep-seated high temperature liquid (oil-gaswater mixture) draws geothermal warming flowing layer to transit heat upward, decreased viscidity and increased fluidity. Weigang Oilfield has high formation temperature, high formation wax precipitation temperature, high geothermal gradient, fast formation temperature variation compensation keep original temperature in well bottom after ten years development. Utilizing sewage recycling development to oi1 field is not only raises water injection temperature, but also enjoy a long term sustained development. Geothermal water flooding is directly use hot water strata, without burning fuel to heat cold water into formation water and which improved oil recovery.

Physical simulation and displacement experiments show that hot water flooding can enhance oil recovery 
(Figure 1). The patents applied by Gudong Oil production plant in Shengli Oilfield and research Institute of Geological Science in Shengli Oilfield Company, select R4-13 as typical well group, which has higher remaining oil saturation, good reservoir connectivity, well-pattern completion, stable production, original oil saturation is $63.8 \%$. Hot water flooding simulations experiment was carried. Displacement efficiency increase with displacement pore volume increase; concentration increase, displacement efficiency increase gradually; displacement efficiency increase with injection water temperature increase. As long as water temperature is higher than oil and reservoir temperature, significantly improve extraction effect, so enhanced oil recovery.

Stimulation using steam needs burn crude oil, while steam injection thermal efficiency process is relatively low. Hot water flooding by geothermal resources with simple principle, verified by experiments, saved trouble, money and economized fuel, widely used in other different reservoirs, safe operation, low energy consumption and environmental protection, with wide applicability and broad prospect application.

\subsection{Chinese Geothermal Resources Development and Utilization}

Geothermal resources is premise to realize geothermal oil recovery. Abundant geothermal resources reach 300 Etoe on the earth, recoverable reserves in $10-20$ years, as many as 11.9 Gtoe, which corresponds one year's global TPES (total primary energy supply). In China, geological survey and exploration discoveries geothermal resources, just next to USA in geothermal resources reserve, become the world's secondary richest geothermal resources country. According to general calculations, heat resources is converted into 100 cubic meters, $85^{\circ} \mathrm{C}$ geothermal fluids is equivalent to one ton of standard coal heat value. The major sedimentary basins in China is approximately 91 million square kilometers, total storage

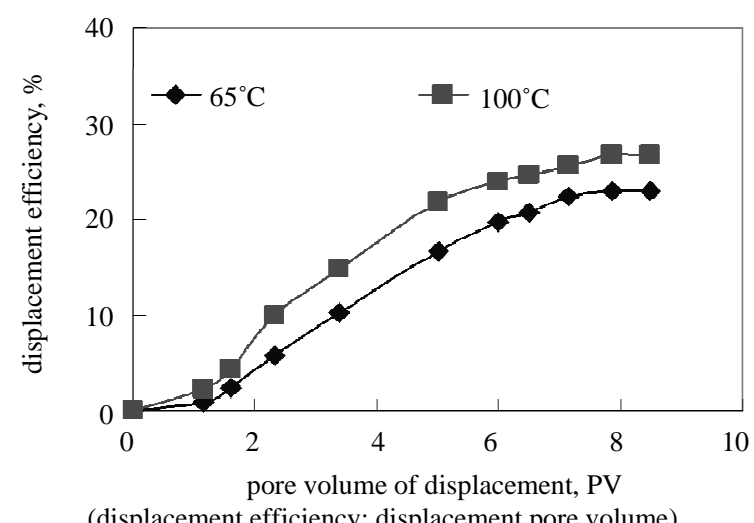

Figure 1. Hot water oil expulsion process physical modeling in Gudong Oilfield. geothermal resources within 2000 meters depth, is equivalent to 37 trillion tons standard coal calorific value, take its recovery as $1 \%$, may be obtain lower recoverable reserves limit of geothermal resources equivalent to 13.7 billion tons of standard coal. Mined for 100 years with the plan production rate is $1 \%$. At present, China has nearly 2500 geothermal wells, the depth from hundreds meters to 4000 meters, total annual development geothermal water is estimated at 5 billion cubic meters, geothermal energy is equivalent to 500 million tons of standard coal heat value. China has proved geothermal reserves about 4600 hundred million tons standard coal, utilization is $1 / 1000000$.

In Gudong Oilfield, grown from bottom to top three oil-bearing stratas as Shahejie, Dongying, Guantao formation, reservoir depth is $1100-3800 \mathrm{~m}$, oil-bearing intervals length is $2700 \mathrm{~m}$, normal pressure and normal temperature systems, temperature differences from $48^{\circ} \mathrm{C}$ to $169^{\circ} \mathrm{C}$. Formation pressure measured by electronic pressure gauge, all section and setting depth of inclined wells and horizontal wells are converted into vertical depth. From 3400 valid samples, statistical results showed that formation temperature is proportional to reservoir depth in Gudong Oilfield (Figure 2), deeper buried, higher temperature. The temperature difference between layers provided heat source. Deep oil reservoir's (Dongying, Shahejie) temperature is higher than shallow oil reservoir (Guantao) to $40^{\circ} \mathrm{C}-70^{\circ} \mathrm{C}$, so deep oil reservoir can choice as geothermal resources for shallow oil reservoir. Deep active edge and bottom water body can choice as geothermal resources, if it found formation with abnormal high temperature could be ideal. Deep-burial, bigger water body, less oil production, more fluid supply capacity, some wells are selected as geothermal resources in Gudong Oilfield. If output fluid form deep reservoir such as Shahejie injection into Guantao, achieve the same result with conventional thermal recovery methods. There-

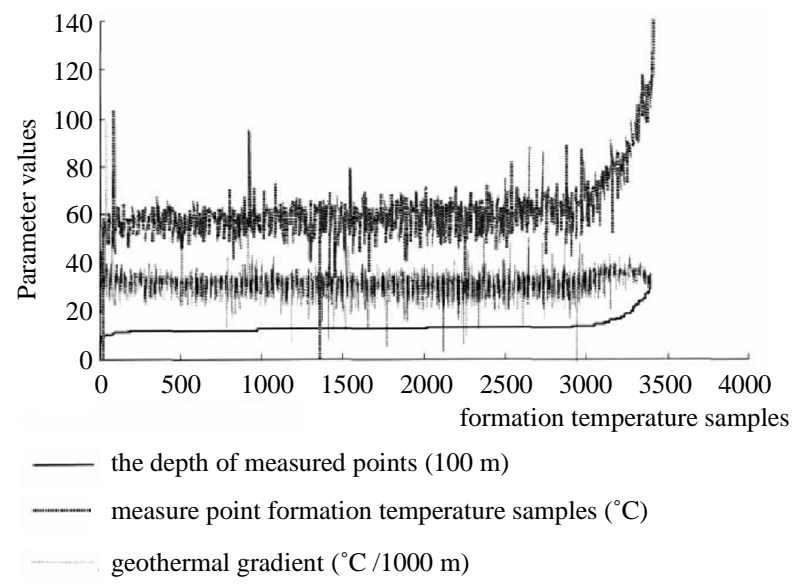

Figure 2. Relationship between reservoir depth and temperature in Gudong Oilfield. 
fore, this article requirements broad geothermal concept, is not rigidly adhere to typical geothermal. Of course, we can drill special geothermal water source wells.

Gudong 18 block Shahejie Formation temperature is $114.3^{\circ} \mathrm{C}, 9$ block in Gudong Oilfield is typical heavy oil block, hot water flooding will be carry out by Gudong 18 block geothermal resources (Table 2). According to Gushen 2 well viscosity-temperature curve, inflection temperature is $50^{\circ} \mathrm{C}$, crude oil viscosity decline rapidly from $3949 \mathrm{mPa} \cdot \mathrm{s}$ to $1671 \mathrm{mPa} \cdot \mathrm{s}$, heavy oil flow and shaft lifting problems are solved.

\subsection{Necessary Technologies}

Huabei, Daqing, Zhongyuan Oilfields geothermal already as take advantage by utilization oil production equipment, water source heat pump technology already mature. Heavy oil blocks is geothermal oil recovery dominant. Under the promotion of technological progress and high oil price, thermal flooding include thermal recovery by steam injection, in-situ combustion, thermal water flooding in American has some excellent characteristics, such as large scale and obvious effect. In China, we have organized steam huff and puff of heavy oil research since 1980s, carried out steam drive technology research of heavy oil in 1990s, heavy oil production by thermal recovery is $3350 \times 10^{4} \mathrm{t}$ in 2010 . Willman calculate maximum heating radius of cyclic steam stimulation is $40 \mathrm{~m}$. Cored well is drilled only $80 \mathrm{~m}$ distance nearby old thermal production wells in Gudao Oilfield, enriched residual oil, cyclic steam stimulation heating radius is less than $80 \mathrm{~m}$, confirmed current well pattern such as $200 \mathrm{~m}$ $\times 283 \mathrm{~m}$ has encrypt well pattern potentials. Development mode switching on heavy oil thermal recovery blocks has three major conversion: First, infilling drilling tapping residual-oil potential. In Gudong Oilfield, detailed reservoir characterization and residual oil quantitative research, several adjustment measures have been taken [6], production Kendong 521, Kendong 53 block layer subdivision, sweep well pattern thickening Gudong 9 block, Ken 92 block, put into 28 new wells, oil productivity increased $7.0 \times 10^{4}$ t, new infilling well incremental recoverable reserve is $1.7 \times 10^{4} \mathrm{t}$. Secondly, Optimization study on convert development scheme after cyclic steam stimulation, for conventional heavy oil reservoir. New thermal wells are infilled in Gudao Oilfield, achieve water flooding conversion to steam stimulation, oil productivity increased $12.0 \times 10^{4}$ t. Thirdly, intermission steam flood.

Sophisticated technologies on improving heat utilizetion efficiency have formed. The first part is protected properly after drilling, operation, steam injection during operation process down hole operation, using pre-stress cementing, enhance oil well perfects through large pore, deep drill negative perforate and under balance perforating technique, improve seepage flow capability through high pressure packing, wire wrapped screen sand control, extend sand control life, heavy oil profile control by nitrogen injection in Gudong Oilfield, steam injection pressure improved 4.9 $\mathrm{MPa}$, steam temperature rise $51^{\circ} \mathrm{C}$, see oil time shortened $5 \mathrm{~d}$, water invasion rate is controlled effectively. Second, steam injection pressure riased from $17 \mathrm{MPa}$ to $21 \mathrm{MPa}$ by supercritical pressure subcritical boiler, steam injection pressure increased from 8.7 MPa to 11.7 MPa by stratified steam injection in Gudong R3N11 well, steam temperature of $299^{\circ} \mathrm{C}$ up to $307^{\circ} \mathrm{C}$, daily production from $3.5 \mathrm{t} / \mathrm{d}$ up to $8.5 \mathrm{t} / \mathrm{d}$. Third, achieving shorten steam injection period, energy loss were reduced after steam, "steam injection-chokeblowout-killing well, sand-cleanout-pump-oil production" reduced "steam injection-choke-blowout-oil production”, choke time reduced 3d. Fourth, enhance lifting ability by sand-carrying, chain-type pumping unit and viscosity reducer. Improve heavy oil developed reserves factor, oil recovery rate and heat energy application, provide a favorable foundation to geothermal oil recovery [7-9]. In addition, Professor Roland Horne in American

Table 2. Primarily-selected geothermal fountain wells in Gudong Oilfield.

\begin{tabular}{|c|c|c|c|c|c|}
\hline well & producing interval & $\begin{array}{l}\text { reservoir Depth } \\
\text { (m) }\end{array}$ & $\begin{array}{l}\text { reservoir temperature } \\
\qquad\left({ }^{\circ} \mathrm{C}\right)\end{array}$ & $\begin{array}{l}\text { temperature gradient } \\
\qquad\left({ }^{\circ} \mathrm{C} / 100 \mathrm{~m}\right)\end{array}$ & $\begin{array}{l}\text { daily fluid production } \\
\text { Capacity (t/d) }\end{array}$ \\
\hline GD69X12 & ES1 & 2347.3 & 112.77 & 3.946 & 21.8 \\
\hline GD68-1 & ES3 & 2510 & 116.28 & 3.830 & 181.5 \\
\hline GD281-5 & ES3 & 3636.2 & 141.3 & 3.332 & 9.1 \\
\hline $4-14-211$ & ES1 & 2500 & 111.56 & 3.656 & 20.7 \\
\hline GD301 & $\mathrm{ES}^{3}$ & 3250 & 126.1 & 3.260 & 14.7 \\
\hline GD301-1 & ES2 & 3005 & 121.68 & 3.379 & 7.6 \\
\hline GD18-21 & ES3 & 2750 & 114.33 & 3.425 & 5.9 \\
\hline
\end{tabular}


Stanford University, studied geothermal resources effectively production in different aspects, based on laboratory, research geothermal resources injection reservoir (such as hot springs).

\subsection{Geotherm Oil Recovery Implementation}

Shengli, Daqing, Huabei and Dagang Oilfields have geothermal resources, industrial tests have been carried out, such as substitution heater by middle high temperature water, groundwater heat pump. As reservoir and fluid temperature is positive correlation with depth, there is deep differences, it could form a temperature difference, all Oilfields have geothermal resources. The key is how to use geothermal resources, we can choose a special geothermal resources well, provide hot water; existing deep wells can also be extracted fluid, in order to reduce heat loss, not separate oil, gas and water, and without ground, injected directly into the reservoir purpose [10]. Deep active edge and bottom water body can choice as geothermal resources, this paper designs 7 conceptual geotherm oil recovery models.

Model I: deep-seated high temperature liquid (oil-gaswater mixture) draws geothermal warming flowing layer to transit heat upward, both drilling multi-branch well and injection-well at the same position, use free-pressure pump to inject hot liquid directly to aimed oil layer, and making oil recovery in the surrounding wells.

Model II: drill a multiple lateral horizontal well as injection-well, decreases heat loss of liquid within wellbores, without surface gas-liquid separation, use freepressure pump to inject hot liquid directly to target layer, without soak unloading, making oil recovery in the surrounding wells.

Model III: Focusing on decreasing producing water cost, improving injectted temperature, achieve hot water flooding. Low temperature water injected into hot dry rock in the underground will became high temperature and pressure supercritical fluid (steam or hot water), produce a certain direction fracture system, thus form heat storage structure. Chosen appropriate point to drill through heat storage structure, hot water sprayed out can be used. Deep drilling or water flooding is very mature. Rich developing experience accumulated will provide convenience to use hot dry rock. The hot dry rock auxiliary developing pilot test should be carried out in favorable blocks first. Figure 3 is hot dry rock assist oil recovery technique design. A well is injection cold water well, B well is water recovery well or steam recovery well, C well is injection hot water well, D well is production well, both injection well and production well should be used as far as possible for horizontal branch well.

Model IV: Geothermal fountain well produced hot liquid from steam flood well, without surface gas-liquid

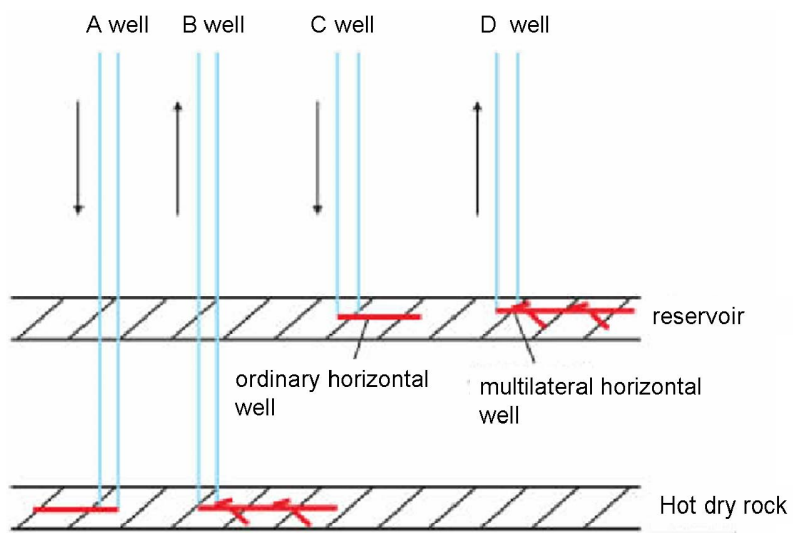

Figure 3. Hot dry rock assist oil recovery technique design schematic.

separation, steam flood well inject hot liquid directly to target layer.

Model V: Cyclic water injection. Produced hot liquid from geothermal fountain well without surface gas-liquid separation, directly inject to oil well. But surface, oil wellbores, unloading made large heat loss.

Model VI: Geothermal fountain well produced hot liquid, after surface gas-liquid separation in oil production station, inject to target layer. But gas-liquid separation, surface, oil wellbores, unloading made large heat loss.

Model VII: There is a heating oil recovery process with the method of the earth thermal energy self-Balance [11]. Huabei Oilfield Chu 32 Well, the results indicate that effect is obvious by using the earth thermal energy self-balance method to heat liquid, oil temperature at the well outlet increases oil production enhancement and oil pump depth, basically linear with them.

Some technical measures of Conceptual model design I made large heat loss. production Fluid is likely above $100^{\circ} \mathrm{C}$, while retain temperature after injection only $50^{\circ} \mathrm{C}$ in aimed oil layer, actually mostly the same except for minor differences to reservoir temperature, can not meet thermal recovery requirement [12]. For example, injected water main derived from produced water reinjection, produced fluid temperature wellhead near formation temperature, after a long process from borehole lifting, oil pipeline, oil production station, water injection system surface pipelines, single well injection lines, wellbore, formation, even water sources temperatures as high as $70^{\circ} \mathrm{C}$, only $35^{\circ} \mathrm{C}$ in reservoir after injection, high temperature advantage has lost. Injection water practice proven that: isothermal develop injection water effective than cold water injection, in Chengdao Oilfield. Concepttual Model I is also better than actual injection process, because it can improve injection water temperature.

On one hand, to take deep thermal fluid advantage, don't with fluid mixing shallow development and reduce ground temperature. On the other hand, the deep heat 
source can be individually designed and well as into water. From improve thermal efficiency view, Option III is best, program II is more feasible.

\subsection{Progress and Prospects}

$70 \%$ Liaohe oilfield exploitation oil resources is heavy or ultra heavy oil, lot crude oil burned every year. To save energy, Ci Yutuo, Liaohe Oilfield Exploration completed mining geothermal resources such as oil fields, delineation of geothermal Tianyou Li block 11. In 2006, oil production plant of Shenyang built the first geothermal demonstration project, two geothermal well were drilled, single well production reach to $1500 \mathrm{~m}^{3}$ per day, well water from overflow, water temperature is $64^{\circ} \mathrm{C}$. Water poolied after $9 \mathrm{~km}$ pipeline to water treatment station, iron and heat transfer groundwater. Similarly, in October, 2007, Gudong Oil Production Plant No. CWS on behalf of the Union Station project is put into oil, 2 sets 10 tons /hour steam boiler and 22 sets coal-water slurry oil, gas, heat exchanger.

Heat oil and realizing premise is heat. As fluid reservoir temperature has a positive correlation with depth, as long as the deep is difference, it will form a temperature difference, so that almost all the oil fields could have geothermal resources. The key is how to use geothermal resources, we can choose a special place heat well, provide hot water; existing deep wells can also be extracted fluid, in order to reduce heat loss, without oil, gas and water separation, without ground, injected directly into the reservoir purpose.

Need is technological progress driving force, practice is invention source in 2009, the deep geothermal engineering technology was identified as Chinese energy technology development's technical direction. With world demand for clean energy, will use greater geothermal energy. Gudong heavy oil block is thin, water activity and other deficiencies, after many rounds of subthroughput, contradiction for high cost of mining faces, thermal utilization is low and large production decline. In new historical period, crude oil production can not meet national economic development needs, while mining remaining resources cost is gradually increasing, for looking to take over low-power technology development heat oil. Focuses on scientific quality and technological innovation, geothermal oil production is simple in principle, local materials and energy consumption saving significantly. Ready-made available to heat source wells which are mainly those fall deep exploration wells. From technical argument to decision-making, to the industrial application, require lot works. Second is how to reduce heat loss process, thermal recovery development can learn from successful experience, take some specific measures to heat transfer fluids. Deep fluid recovery not injected into heavy oil-water separation, directly to the oil layer.

Chinese heavy oil thermal recovery and water injecttion process technology is mature, so as it provide hot water extraction convenience to geothermal resources, method principle is clear and easy to implement, widely applicable to other reservoir types, safety, energy conservation, environmental protection, broad applicability, broad application prospects. We concluded that two important reasons of geothermal. first, crude oil has higher value-added than geothermal resources; Second, crude oil transportation is easier than geothermal resources, similar to coal development in Shanxi, transportation is more convenient, expanding application scope, also improve economic efficiency.

The author suggest that not only note enough water, but also note good water injection, as moderate to strong proponent of water, less dry remedy, put an end to destructive mining in the basic functions to meet water after injection, which not only help reduce injection water damage, but also saves water costs, why refused.

\section{Conclusions}

1) Water temperature is too low for current injection effect on oil field development adverse effects and put forward some constructive suggestions, injected water to overcome low temperature on cold injury, is an important way to improve injection water temperature. Meanwhile, burned crude oil to produce steam need change. Proposes that broad-rich geothermal resources and existing technical equipment for geothermal water oil idea, carried through deep high-temperature geothermal heating shallow fluid reservoir to reduce oil viscosity, improve mobility and improve development effect performance.

2) Heat oil principle by geothermal is simple, easy to implement, widely applicable to reservoirs types, safety, energy saving, environmental protection, with broad applicability and broad application prospects. Within proposed field geothermal resources survey, heavy oil block in enabling first pilot test carried out in hot oil.

3) Based on Gudong Oilfield statistics and temperature field variation characteristics, the authors designed geothermal oil recovery flow-chart concept, drill multibranch well as geothermal fountain injection-well at the same position, use free-pressure pump to inject hot liquid directly to aimed layer, make oil recovery in the surrounding wells. It is proposed that geothermal oil recovery forerunner test should be first conducted in favorable blocks.

\section{REFERENCES}

[1] Q.-T. Yu, "Proceedings on Oilfield Development," Petroleum Industry Press, Beijing, 1999, pp. 129-135.

[2] T.-D. Li, "Main Advances and Achievements in the Spe- 
cial Subject Study of the 3D Lithospheric Structure of China," Geology in China, Vol. 33, No. 4, 2006, pp. 689699.

[3] Z.-S. Han, W.-Y. Ran and H.-B. Tong, "Exploration and Evaluation of Shallow Geothermal," Geology in China, Vol. 34, No. 6, 2007, pp. 1115-1122.

[4] Y.-Z. Tang, W. Qi and S.-W. Liu, "Paleozoic Hydrothermal Sedimentary Basin and Hydrothermal Sedimentary Mineralization in the Southern Qinling," Geology in China, Vol. 34, No. 6, 2007, pp. 1091-1101.

[5] J. Duo, "The Basic Characteristics of the Yangbajing Geothermal Field-A Typical High Temperature Geothermal System,” Acta Geoscientia Sinica, Vol. 34, No. 1, 2001, pp. 10-17.

[6] X.-Z. Wang and L.-F. Zeng, "Effect of Practical Techniques in Producing Remaining Oil in Gudong Oilfield,” Petroleum Exploration and Development, Vol. 35, No. 4, 2008, pp. 467-475.

[7] K. Yang, Z.-H. Fan and N.-S. Zhu, "Comprehensive Adjustment of Development Mode of Common Swage Recycling in Weigang High Pour Point Oil Field,” Petroleum Exploration and Development, Vol. 29, No. 2, 2002, pp. 94-96.
[8] S.-Y. Yuan, S.-Y. Liu and Y.-T. Zhang, "Enhancing Heavy Oil Recovery with Hot Water Flooding by Adding Nitrogen and Surfactant,” Acta Petrolei Sinica, Vol. 25, No. 1, 2004, pp. 57-61.

[9] H.-M. Zhang, L.-S. Cheng and L. Liang, "The Numerical Simulation of Hot Water Flooding with Suffactant in Heavy Oil Reservoir,” Xinjiang Petroleum Geology, Vol. 23, No. 1, 2002, pp. 52-54.

[10] X.-Z. Wang and J.-Y. Wang, "Study on Feasibility of Geothermal Oil Recovery in Gudong Oilfield," FaultBlock Oil \& Gas Field, Vol. 23, No. 1, 2008, pp. 126128.

[11] Y.-C. Wang, J.-J. Zhang and R.-J. Wang, "Numerical Simulation of the Heating Oil Recovery Process with the Method of the Earth Thermal Energy Self-Balance,” Journal of Beijing Institute of Technology, Vol. 25, No. 1, 2005, pp. 1-5.

[12] X.-Z. Wang, J.-Y. Wang and C.-F. Wang, “Quantitative Description of Characteristics of High-Capacity Channels in Unconsolidated Sandstone Reservoirs Using in Situ Production Data,” Petroleum Science, Vol. 7, No. 1, 2010, pp. 106-111. doi:10.1007/s12182-010-0013-0 